\title{
Quality of Life and Negative Affectivity at the Patients with Stroke and Musculoskeletal Disorders
}

\author{
SZAKÁCS Juliánna ${ }^{1}$, DUICA Lavinia-Corina ${ }^{2,3}$, RACHERIU Mihaela ${ }^{2,4}$
}

Editor: Mihail HOTETEU, Romanian Association of Balneology, hoteteu@yahoo.com

Reviewers: Constantin Munteanu and Gabriela Dogaru

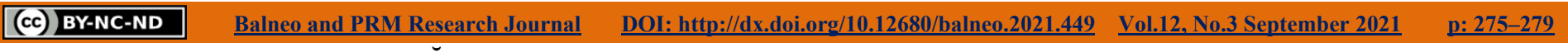

*Corresponding author: DUICĂ Lavinia-Corina, E-mail: lavinia.duica@ulbsibiu.ro

${ }^{1}$ George Emil Palade University of Medicine, Pharmacy, Science, and Technology of Targu Mures, Faculty of Medicine, Department of Biophysics, Targu Mureș, Romania

${ }^{2}$ Lucian Blaga University of Sibiu, Faculty of Medicine, Sibiu, Romania

${ }^{3}$ Hospital of Psychiatry „Doctor Gheorghe Preda” Sibiu, România

${ }^{4}$ County Clinical Emergency Hospital, Sibiu, Romania

\begin{abstract}
Introduction. Stroke can be a severe debilitating medical condition due to its medical consequences. When it occurs at an individual with pre-existent musculoskeletal disorders, the medical recovery becomes more problematic. Some consequences, like negative affectivity and a reduced quality of life intervene to varying degrees.

Material and method. Our study included 150 outpatients who were diagnosed with stroke and one of five types of musculoskeletal disorders (low back pain, osteoporosis, hand disorders, hip osteoarthritis, knee osteoarthritis). We divided all the patients in five sub-groups. To assess the negative affectivity (anxiety) and quality of life we administered to the patients two scales: the State Trait Anxiety Inventory (STAI) form X1 (anxiety a s a state) and form X2 (anxiety as a trait) and The Quality of Life (QOL).

Results. In patients diagnosed with stroke and osteoporosis, the quality of life was $83.92 \%$ of the maximum value. Anxiety as a state rated at an average of 50.5 and anxiety as a trait rated at an average of 45 . In the case of stroke and degenerative diseases at the lower limbs, we registered the quality of life of $77.68 \%$ in knee osteoarthritis and $75.89 \%$ in hip osteoarthritis; anxiety as a condition had an average value of 65 and, as a trait, a value of 63 in knee osteoarthritis, while in hip osteoarthritis the anxiety as a condition, and, in the same time, as a trait, rated both at 49.5. Low back pain in stroke patients had a quality of life of $77.86 \%$ of the maximum value; anxiety as a condition was 48 and the anxiety trait has the value of 47 . For the patients with stroke and hand disease, the quality of life was assessed at $88.83 \%$. Anxiety as a condition recorded an average value of 48 and the average value of 51 for anxiety as a trait recorded an average value of 51 .

Conclusions. The lowest score of quality of life is recorded in the patient diagnosed with stroke and hip osteoarthritis (75.89\% of the maximum value). This association converges with body dynamics, as the overlap of these two medical conditions may explain reduced functionality. The value of anxiety as a condition and also as a trait was higher in patients with stroke and osteoarthritis of the knee (65 and 63, respectively). The latter result is understandable, as intense pain and, therefore, discomfort related to osteoarthritis of the knee is well known.
\end{abstract}

Keywords: stroke, anxiety, quality of life, musculoskeletal conditions,

\section{INTRODUCTION}

Stroke is considered a public health issue (1) due to its economic, medical and family consequences, the 35-70 age group being the most affected, with an annual incidence of 300 new cases / 100,000 inhabitants.

Stroke causes significant motor deficit, sensory deficit, postural control and language deficit (2). There is an increase in the number of patients who are diagnosed with stroke, mainly due to the aging of the population (3).

There are studies which show that there is a link between inflammation and an ischemic stroke, as it happens in stroke (4).

Therefore, the C-reactive protein marker is correlated with the prognosis and severity of the disease, but at the same time in connection with the degree of motor deficit quantified by the MRC scale $(5,6)$.
The study of Langhorne made in 2017 (7) shows that the incidence of stroke has a higher increase in males in comparison to females.

Motor recovery is mainly determined by the time parameter and in the first 3 months after the stroke shows restriction $(8,9,10)$.

One of the most important goals for the recovery of a patient who suffered from stroke is to restore the function of the affected lower limb, which will first enable the patient's independence, as well as to have an orthostatic position, to achieve gait and to avoid the falling risk. In this context it is important to regain strength and motor control at this level, which is necessary to maintain stability and body posture (11). 
After a complex assessment, a neuromotor recovery program can be quantified to address the members of the affected hemi body (12). It is very easy to recover the upper limb by means of an individualized physical therapy program (13).

Even if the patient does not change his static balance during the gait recovery period, there are still significant improvements for the dynamic balance.

For the patient diagnosed with stroke, it is very important, first of all to resume the daily activities, but also the abilities to walk, to be independent, as well as cognition and language.

All daily activities are consistent with the patients' clinical conditions at a given time, but they also depend on the severity of stroke $(14,15,16)$, and on the progress made for motor activities, especially in the first weeks (1, 17,18).

Therefore, the patient's recovery occurs in a certain order: personal care, getting dressed, walking and, at the end of the first recovery period, going upstairs and downstairs.

For the recovery of abilities, it is important, first of all to recover the active control at the level of the radiocarpal joints, for the extension of the fingers, useful especially in the first 72 hours after the stroke $(19,20)$.

As for the walking ability, this is correlated with motor deficit in the foot and immobility of movement $(1,14,21$, 22, 23)

An important element is the independent balance achieved in the sitting position as well as the existing force at the level of the hemiparetic leg.

The most important factor in the resumption of the gait independence is the improvement of balance in orthostatism $(24,25)$. It is correlated with the motor function of the foot and independent gait.

The establishing of the prognosis in the gait recovery after stroke depends on the balance control $(26,27,28,29)$. There are studies which show that the MBT physiotherapy device has a role in forming and training postural balance, not only in patients with stroke, but also in patients with certain musculoskeletal disorders (2).

There are some situations in which the stroke occurred and caused hemiparesis on a hemi body, and in the respective upper limb there is already a post-traumatic injury of the tendons of the flexors or of the extensors.

The symptoms that are added to the existing one through the stroke are represented by pain, joint stiffness, decreased functional capacity and muscle atrophy. In this context, the patient with stroke needs the physiotherapy indicated for recovery in stroke, and, also, other recovery procedures, such as hydrotherapy and massage.

The purpose of the physiotherapy program is to enable the reintegration of the hand into the kinetic chain of the upper limb and as much as possible the mobilization of both hands. It is also possible to use laser with analgesic and trophic-vascular effect, ultrasound, as well as electrostimulation, in order to relax the spastic muscles (30).

The hand, the most important segment of the body, has a role in gestures and functionality as well as in performing daily activities. It is estimated that the incidence of this pathology is about $0.125 \%$ - $1 \%$ / year, with a prevalence of $5-15 \%$, which affects especially females. The carpal tunnel syndrome causes disability with family, professional, economic and social consequences. Recovery is conservative (the use of ultrasound, laser, physiotherapy, orthosis), but also by surgery (31).

The patient who suffered from stroke may be an elderly person, previously diagnosed with obesity and a degenerative disease in the hip or knee. In the case of patients with neurological disease (stroke) who also have obesity accompanied by diseases of the musculoskeletal system (hip osteoarthritis, knee osteoarthritis) (32)

Recovery treatment involves the use of laser, ultrasound, physiotherapy, to enable the restoration of the agonistantagonist muscle balance, the restoration of static and dynamic balance, as well as the increase of joint mobility $(33,34,35,36)$.

There are patients who suffered from stroke and who were previously diagnosed with low back pain for which they received treatment. The coexistence of the two diseases leads to the use of ultrasound in the lumbar area in the form of sonotherapy (37), by using locally administered pharmacological products of NSAID- type (38).

Ultrasound has been used for the effect of pain reduction, muscle relaxation and for the hyperemic effect $(39,40)$.

Another pathology that can be found in patients diagnosed with stroke is osteoporosis, which is a systemic disease that affects the structure and density of bones. Recovery mainly involves physical therapy associated with pharmacological treatment for long periods (41).

Ultrasound is applied in these pathologies associated with stroke, in order to reduce the pain component particularly, but also to reduce joint stiffness and muscle contracture, and for the local effect of increasing local temperature (42).

Nonsteroidal anti-inflammatory drugs (Diclofenac) have been administered locally by sonophoresis, and in combination with decontracting medication, antispasmodics, massage and physical therapy, especially neuroproprioceptive facilitation techniques. It is useful in people diagnosed with stroke and other musculoskeletal disorders, in acute, subacute and chronic stages (43, 44, 45).

Patients with stroke may have other types of neurological disorders: Parkinson's disease, depression, Alzheimer's disease $(46,47)$.

The purpose of this study was to assess the anxiety of patients diagnosed with stroke and who had other musculoskeletal disorders. 


\section{Material and method.}

The study was cross-sectional and was conducted on an outpatient basis. It included 150 patients who were diagnosed with stroke, but who were previously diagnosed with musculoskeletal disorders such as hand, spine or degenerative diseases of the lower limbs. Thus, there were 4 groups according to the presented condition.

The State Trait Anxiety Inventory (S.T.A.I.) scale was used to assess anxiety, which includes two self-assessment scales to assess and measure two distinct concepts of anxiety, namely anxiety as a state (S.T.A.I.-X1) and anxiety as a trait (S.T.A.I.-X2)

In order to assess the patients' quality of life, the QOL (Quality of life) scale was used, which assesses the physical and mental health with the help of the 16 items. The minimum value is 16 and the maximum value is 112 . 1st Group, which is the group of patients diagnosed with stroke and osteoporosis, included 14 people, distributed by age groups as follows: a person in the age group 41-50, 4 people in the age group 51-60, 7 people in the age group $61-70$ and 2 people in the age group over 71.

The group of patients diagnosed with stroke and degenerative diseases of the lower limbs included 80 people.

Group 3 is the group of patients diagnosed with stroke and who had low back pain. It included 23 women and 13 men.

There were 20 patients diagnosed with stroke and hand disorders (group 4), of which 11 were male and 9 were female (Table no.1).

\section{Results}

In patients diagnosed with stroke and who had osteoporosis, the quality of life was assessed by using the QOL scale at $83.92 \%$ of the maximum value.

Anxiety as a condition was rated on average at 50.5, which means that anxiety caused by the disease is slightly perceived. As a trait, anxiety was rated at an average of 45 , meaning that patients experience anxiety occasionally but persistently.

For patients diagnosed with stroke and degenerative hip disease, the quality of life was assessed at $75.89 \%$ in comparison to the maximum value on the QOL scale.

Anxiety as a condition, on average, was assessed at 49.5, which places the patient's assessment between little and enough. Anxiety as a trait recorded average values of 51, i.e., this condition was sometimes perceived by patients.

For patients diagnosed with knee osteoarthritis, their quality of life was perceived at $77.68 \%$ of the maximum value assessed by using the QOL scale.

Anxiety as a condition had an average value of 65 , which places the value of this parameter to the significance quite affected. Anxiety as a trait recorded a value of 63 , which shows that patients often perceive anxiety and its related symptoms.
Low back pain in stroke patients had a quality of life of $77.86 \%$ of the maximum value assessed on the QOL scale.

Anxiety as a condition, caused by the disease, had an average of 48 which shows that patients slightly feel anxiety related to the diseases they have. The average value of 47 for anxiety as a trait shows that patients sometimes feel anxiety or fear.

For patients with stroke and hand disease, the quality of life was assessed at $88.83 \%$ of the maximum value on the QOL scale.

Anxiety as a condition recorded an average value of 48 in these patients, the patients slightly feel the disease. Anxiety as a trait recorded an average value of 51, which indicates that from time to time they have certain conditions that fall into anxiety as a trait (Chart no.1).

\section{Table no.1 Distribution of patients}

\begin{tabular}{|c|c|c|c|c|c|c|c|}
\hline \multirow[t]{2}{*}{ Group } & \multirow{2}{*}{$\begin{array}{l}\text { Disease } \\
\text { associated with } \\
\text { stroke }\end{array}$} & \multirow[t]{2}{*}{ Gender } & \multirow{2}{*}{$\begin{array}{l}\text { Number of } \\
\text { patients }\end{array}$} & \multicolumn{4}{|c|}{ Age group } \\
\hline & & & & 41-50 & $51-60$ & $61-70$ & $>71$ \\
\hline 1st Group & Osteoporosis & Female & 14 & 1 & 4 & 7 & 2 \\
\hline \multirow{4}{*}{$\begin{array}{l}\text { 2nd Group } \\
\text { (Degenerativ } \\
\text { e diseases at } \\
\text { the lower } \\
\text { limbs) }\end{array}$} & \multirow[t]{2}{*}{ Coxarthrosis } & Female & 11 & \multirow[t]{2}{*}{12} & \multirow[t]{2}{*}{8} & \multirow[t]{2}{*}{6} & \multirow[t]{2}{*}{4} \\
\hline & & Male & 19 & & & & \\
\hline & \multirow{2}{*}{$\begin{array}{l}\text { Knee } \\
\text { osteoarthritis }\end{array}$} & Female & 25 & \multirow[t]{2}{*}{6} & \multirow[t]{2}{*}{17} & \multirow[t]{2}{*}{19} & \multirow[t]{2}{*}{8} \\
\hline & & Male & 25 & & & & \\
\hline \multirow[t]{2}{*}{ 3rd Group } & \multirow[t]{2}{*}{ Low back pain } & Female & 23 & \multirow[t]{2}{*}{11} & \multirow[t]{2}{*}{13} & \multirow[t]{2}{*}{10} & \multirow[t]{2}{*}{2} \\
\hline & & Male & 13 & & & & \\
\hline \multirow[t]{2}{*}{ 4th Group } & \multirow[t]{2}{*}{ Hand diseases } & Female & 9 & \multirow[t]{2}{*}{7} & \multirow[t]{2}{*}{8} & \multirow[t]{2}{*}{3} & \multirow[t]{2}{*}{2} \\
\hline & & Male & 11 & & & & \\
\hline
\end{tabular}

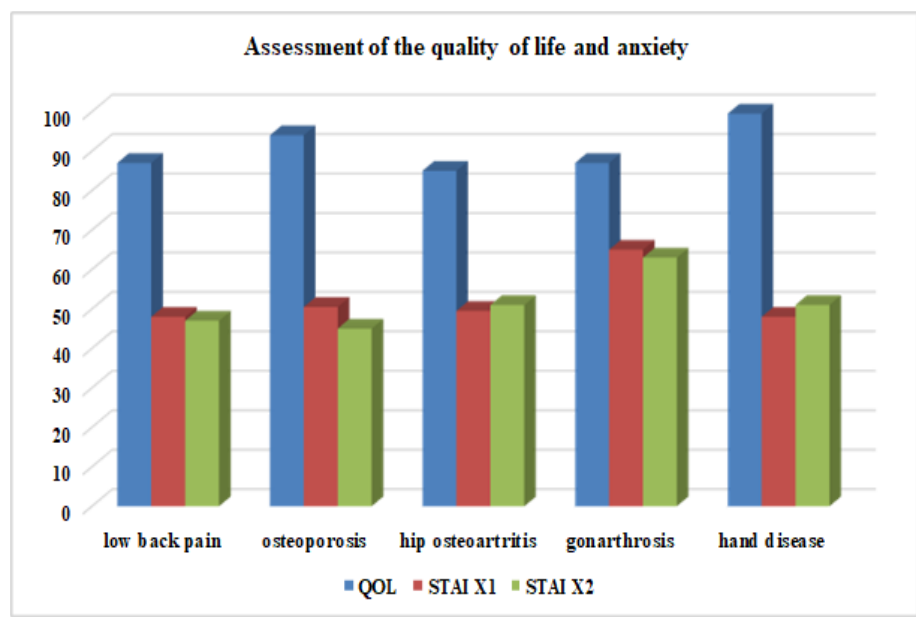

Chart no. 1 Assessment of the quality of life and anxiety

\section{Discussions}

For these patients diagnosed with stroke and other musculoskeletal disorders, the quality of life recorded values between $75.89 \%$ and $88.83 \%$ of the maximum value assessed by the QOL scale, but patients with low back pain, those with gonarthrosis and those with hip osteoarthritis recorded higher values. 
Anxiety as a condition caused by the disease recorded average values between 48 and 65 when applying the S.T.A.I. X1 scale, with lower values, i.e., a lower perception of this condition in patients diagnosed with low back pain and hand disorders and with a higher value for patients with knee osteoarthritis.

Anxiety as a trait assessed by using the S.T.A.I. X2 scale recorded average values between 45 and 63 with low values for patients diagnosed with osteoporosis and low back pain in addition to stroke, and the maximum value also in patients with knee osteoarthritis.

Therefore, patients diagnosed with stroke and knee osteoarthritis have anxiety as a condition and as a trait with higher calories.

\section{Conclusions}

Overall, the lowest score of quality of life registered at the patient diagnosed with stroke and hip osteoarthritis ( $75.89 \%$ of the maximum value).

This association converges with the dynamic of the body because the superposition of these two medical conditions can explain a reduced functionality.

The value of anxiety as a state and, also, as a trait was higher at the patients with stroke and knee osteoarthritis (65, respectively 63$)$.

The last result is understandable since it is well known the intense pain and, thus the discomfort related with knee osteoarthritis.

\section{Author contributions.}

All the authors had the same contribution.

\section{Accordance to ethics standards.}

The study complies with the rules of ethics and deontology according to the legislation in force.

\section{REFERENCES:}

1. Stam HJ, Buyruk HM, Melvin JL, Stucki G, Burggraaf IB. Recuperarea medicala de faza acuta. Bucuresti: Editura Universitara „Carol Davila”; 2012. ISBN:978-973-708-8796.

2. Danelciuc FT, Silisteanu SC, Danail S. The increase of the life quality for patients who had a cerebrovascular accident by using the MBT physiotherapy device. Balneo Research Journal. 2017 MAY; 8(2):40-45.

3. Feigin VL, Lawes CM, Bennett DA, Barker-Collo SL, Parag $\mathrm{V}$. Worldwide stroke incidence and early case fatality reported in 56 population-based studies: a systematic review. Lancet Neurol. 2009 Apr;8 (4):355-369.

4. Duica L, Antonescu E, Totan M, Pirlog M, Silisteanu SC. Contribution of mechanical and electrical cardiovascular factors in patients with ischemic stroke. Pakistan Journal of Pharmaceutical Sciences, 2020; 33:2455-2460.

5. Totan M, Antonescu E, Catana MG, Cernusca Mitariu MM, Roman Filip C, Comaneanu RM, Cernusca Mitariu SI, CReactive Protein-A Predictable Biomarker in Ischemic Stroke. Rev.Chim.(Bucharest). 2019;70(6):2290-2293.
6. Silişteanu SC, Crăciun MD, Antonescu E. Trial on the Possibility to Assess the Static and Dynamic Balance in the Elderly with Diseases on the Level of the Supporting Joints. 2019; E-Health and Bioengineering Conference (EHB).

7. Langhorne P, Bernhardt J, Kwakkel G. Stroke rehabilitation, The Lancet. 2011 May; 377(9778):1693-1702.

8. Thrift AG, Thayabaranathan T, Howard G, Howard VJ, Rothwell PM, et al. Global stroke statistics. International Journal of Stroke. 2017 Jan.;12(1):13-32.

9. Kwakkel G, Kollen B, Lindeman E. Understanding the pattern of functional recovery after stroke:facts and theories. Restor Neurol Neurosci.2004; 22(3-5):281-299.

10. Koyama T, Matsumoto K, Okuno T, Domen KA. New method for predicting functional recovery of stroke patients with hemiplegia:logarithmic modelling. Clin Rehabil. 2005 Oct;19(7):779-789.

11. Boudewijn Kollen et al, Hemiplegic Gait After Stroke: Is Measurement of Maximum Speed Required? Archives of Pfysical Medicine and Rehabilitation. 2006 March; 87(3): 358-363.

12. Silişteanu SC, Antonescu E, Duică L. Strategies for the recovery of patients with post stroke sequelae in the context of the COVID-19 pandemic. 2020; 11(4):507-511.

13. Hingtgen BA, McGuire JR, Wang M, Harris GF. Quantification of reaching during stroke rehabilitation using unique upper extremity kinematic model. Engineering in Medicine and Biology Society IEMBS. 26 ${ }^{\text {th }}$ Annual International Conference of the IEEE, 2004; 7:4916- 4919.

14. Meijer R, van Limbeek J, Peusens G, Rulkens M, Dankor K, Vermeulen M, DE Haan RJ. The stroke Unit Discharge Guideline, a prognostic framework for the discharge outcome from the hospital stroke unit. A prospectice cohort study. Clin Rehabil. 2005 Oct;19(7):770-778.

15. Kwakkel G, Veerbeek JM, Harmeling-van der Wel BC, van Wegen E, Kollen BJ. Early Prediction of functional Outcome after Stroke (EPOS) Investigators.Diagnstic accuracy of the Barthel Index for measuring activities of daily living outcome after ischemic hemispheric stroke:does early poststroke timing of assessmnent matter?. Stroke.2011 Feb; 42(2):342-346.

16. Kwakkel G, van Peppen R, Wagenaar RC, Wood Dauphinee S, Richards C, Ashburn A, Miller K, Lincoln N, Partridge C, Wellwood I, Langhorne P. Effects of augmented exercise therapy time after stroke: ameta-analysis. Stroke. 2004 Nov; 35(11):2529-2539.

17. Verheyden G, Nieuwboer A, Wit LD, Thijs V, Dobbellaere ., Devos H, Severijns D, Vanbereven S, Weerdt WD. Time cours or trunk,arm leg and functional recovery after ischemic stroke.Neurorehabil Neural Repair.2008 MarApr;22(2):173-179.

18. Formisano R, Pantano P, Buzzi MG, Vinicola V, Penta F, Barbanti $\mathrm{P}$, Lenzi GL. Late motor recovery is influenced by muscle tone changes after stroke. Arch Phys Med Rehabil.2005 Feb;86(2):308-311.

19. Smania N, Paolucci S, Tinazzi M, Borghero A, Manganotti P, Fiaschi A, Moretto G. Active Finger Extension. Stroke. 2007; 38:1088-1090.

20. Fritz SL, Light KE, Patterson TS, Behrman AL, Davis SB. Active finger extension predicts outcomes after constraintinduced movement therapy for individuals with hemiparesis after stroke. Stroke .2005 Jun;36 (6):1172-1177. 
21. Wandel A, Jørgensen HS, Nakayama H, Raaschou HO, Olsen TS. Prediction of walking function in stroke patients with initial lower extremity paralysis:the Copenhagen Stroke Study. Arch Phys Med Rehabil.2000 Jun;81(6):736-738.

22. Veerbeek JM, Van Wegen EE, Harmeling-Van der Wel BC, Kwakkel G. EPOS investigators.Is accurate prediction of gait in nonambulatory stroke patients possible within 72 hours post -stroke: The EPOS study. Neuroreahabil Neural Repair. 2011 Mar Apr;25(3):268-274.

23. Kollen B, Kwakkel G, Lindeman E. Time dependency of walking classification in stroke. Phys Ther.2006 May;86(5):618-625.

24. Bagg S, Pombo AP, Hopman W, Effect of age on functional outcomes after stroke rehabilitation. Stroke. 2002 Jan; 33(1):179-185.

25. de Haartt M, Geurts AC, Dault MC, Nienhuis B, Duysens J. Restoration of weight-shifting capacity in patients with postacute stroke: a rehabilitation cohort study. Arch Phys Med Rehabil.2005 Apr;86(4):755-762.

26. de Haart M, Geurts AC, Huidekoper SC, Fasotti L, van Limbeek J. Recovery of standing balance in postacute stroke patiens: arehabilitation cohort study. Arch Phys Med Rehabil. 2004 Jun; 85(6):886-895.

27. Geurts AC, de Haart M, van Nes IJ, Duysens J. A review of standing balance recovery from stroke.Gait posture.2005 Nov;22(3):267-281.

28. van de Port IG, Kwakkel G, Schepers VP. Lindeman E.Predicing mobility outcome one year after stroke: a prospective cohort study. J Rehabil Med. 2006 Jul;38(4):218-223.

29. Buurke JH, Nene AV, Kwakkel G, Erren-Wolters V, Ijzerman MJ, Hermens HJ. Recovery of gait after stroke"what change?. Neurorehabil NeuralRepair.2008 NovDec;22(6):676-683.

30. Silișteanu SC, Haidamac AD. The purpose of the complex treatment for patients with posttraumatic lesions at the hand level. Balneo Research Journal.2016 Dec;7(4): 135-142.

31. Silisteanu SC, Antonescu E, Moisii V. The importance of the recovery treatment in increasing the quality of the lives of the patients with the carpal tunnel syndrome. Balneo Research Journal.2016 Sep;7(3):81-88.

32. Antonescu E, Totan M, Silișteanu SC. The quality of life-an indicator for assessing the recovery program in patients diagnosed with degenerative disorders. Balneo Research Journal. 2020 Jan; 11(1):88-96.

33. Silisteanu SC, Antonescu E, Totan M. Study on the importance of medical treatment and physical methods in recovering patients with knee osteoarthritis. Balneo Research Journal. 2019 May; 10(2):90-97.

34. Silişteanu SC, Silişteanu AE. The importance of the nutrition and of the body weight index in the recovery of the patients older diagnosed with coxarthrosis. Balneo Research Journal. 2017 Feb; 8(1):15-20.

35. Antonescu E, Silişteanu SC, Totan M. Elements of biomechanics correlated to the body mass index in knee osteoarthritis. Balneo Research Journal.2020 Sept; 11(3):379-385.

36. Machet L, Boucaud A. Phonophoresis: efficiency, mechanisms and skin tolerance. Int J Pharm. 2002; 243:115.
37. Silişteanu SC, Antonescu E. The influence of the body weight index (BMI) in the recovery of the degenerative diseases of the joints. Balneo Research Journal.2016 May;7(2):66-71

38. Merrick MA, Bernard KD, Devor ST, Williams MJ. Identical $3 \mathrm{M}-\mathrm{Hz}$ ultrasound treatments with different devices produce different intramuscular temperatures. J Orthop Sports Phys Ther. 2003 Jul;33(7):379-385.

39. Silisteanu SC, Silisteanu AE. The study on the importance of effects after the ultrasound use in the recovery of patients with lower lumbar discopathy. Balneo Research Journal. 2018;9(4):433-437.

40. Ahmadi F, McLoughlin IV, Chauhan S. Bio-effects and safety of low -intensity, low -frequency ultrasonic exposure.Progr Biophys Mol Biol. 2012 Apr;108(3):119138.

41. Silisteanu SC, Silisteanu AE. The importance of physical exercise-bone mass density correlation in reducing the risk of vertebral and non-vertebral fracture in patients with osteoporosis. Balneo Research Journal, 2018 May,9(2):6468.

42. Silisteanu SC, Mitariu L, Ranga R, Antonescu E, Racheriu M, Totan M, Manea MM. Potentiating the Effect of Treatment with Voltaren Gel Using Ultrasonic Frequencies of $1 \mathrm{MHz}$. Rev.Chim. (Bucharest), 2018; 69(7):1749-1751.

43. Shabat S, Folman Y, Leitner Y, Fredman B, Gepstein R. Failure of conservative treatment for lumbar spinal stenosis in elderly patients. Arch Gerontol Geriatr. 2007; 44:235.

44. Silisteanu SC, Antonescu E, Szakacs J, Totan M, Filip CR, Serb BH, Mitariu SIC. Study on Changes in Some Physiological Parameters Under the Action of Therapeutic Ultrasound. Rev. Chim. (Bucharest). 2017; 68(6):13061311.

45. Ebadi S, Ansari NN, Naghdi S, Jalaie S, Sadat M, Bagheri H, Van Tulder MW, Hensche N, Fallah E. The effect of continuous ultrasound on chronic non-specific LBP: a single blind placebo-controlled randomized trial. BioMedCentral MusculoskeletalDisorders. 2012; 13:192-198.

46. Birlutiu V, Stef L, Mitariu SIC, Antonescu E, Parlog M, Purnichi T, Silisteanu SC, Manea MM. The Biochemical Biomarkers Determination in Alzheimer Dementia. Revista de chimie. 2018; 69(11):4055-4059.

47. Duica L, Antonescu E, Pirlog M, Purnichi T, Szakacs J, Totan M, Manea MM. Clinical and biochemical correlations of aggression in Young patients with mental disorders. Revista de Chimie. 2018; 69(6):1544-1549. 